\title{
An Examination of Effects of Student Math Extracurricular Participation on Math Self-efficacy and Proficiency
}

\author{
James M. Durbin \\ Cleveland State University
}

The present study sought to examine if $9^{\text {th }}$ grade students' prior involvement in extracurricular mathematical activities (camps, competitions, clubs, and tutoring) effects students' math self-efficacy and proficiency. In order to examine this the present study utilized the National Center for Education Statistic's High School Longitudinal Study dataset from 2009. Results of the present study indicate having been part of a math club or competition previously has a negative effect on math self-efficacy and a positive effect on math proficiency. This study found that having been part of a math camp previously has a negative effect on a student's math proficiency.

Keywords: Math self-efficacy, Math proficiency, student extracurricular participation

\section{LITERATURE REVIEW}

There are a number of factors that affect a student's classroom success and confidence. Scholars (McKeachie, Pintrich, Lin \& Smith, 1986; Morreale, Backlund \& Sparks, 2014) have indicated that studentto-student and teacher-to-student classroom interactions can have lasting effects on students both while still in the classroom and also once they leave the setting. One gap in this research is examining the effects of student participation in math-based extracurricular activities (e.g. camps, clubs, competitions and tutoring) on students' math based self-efficacy and proficiency.

\section{Math Self-efficacy and Proficiency}

An individual's self-efficacy is defined as how able an individual believes they are to complete a particular activity (Murphy \& Alexander, 2001). This differs from proficiency which is a strategic competence, adaptive reasoning, problem solving, and confidence in computation and calculation (Graven, 2016). The particular importance of examining mathematics with regard to self-efficacy is important since having a lack of confidence is related to both higher levels of mathematical anxiety and stunting of career potential (Bessant, 1995; Yuksel-Sahin, 2008). Scholars (Grigg, Perera, McIlveen, \& Svetleff, 2018; Wu, 2016) have found specifically that students' math self-efficacy has a positive relationship with a student's mathematical proficiency. This relationship has been found to be a reversible in nature, with prior math achievement having a positive impact on students' math self-efficacy. Interestingly, when these scholars examined the connection between math self-efficacy and proficiency, students interest in mathematics predicted self-efficacy, but the inverse relationship did not hold true.

$\mathrm{Wu}$ (2016) examined how to improve student math self-efficacy and proficiency in China and the United States, finding that Chinese students scored higher in both variables. He additionally found that 
levels of math self-efficacy can be increased through greater student classroom involvement and support from others. Thus, it's important to look at how to increase students interests in mathematics, and the effects of extracurricular math activities on student math self-efficacy and proficiency.

\section{Extracurricular Math Activities}

Math clubs, math camps, math tutoring, and math competitions are common student extracurricular activities. According to Hardin (2018) math clubs and competitions can be viewed similarly, in that many competitors are already members of competitive math clubs, but not all math clubs are competitive. Math clubs are conceptualized as a gathering of like-minded people that enjoy math or come together to learn math applications. Hardin indicates that many math clubs are formed to help kids associate mathematics with having fun, to push them beyond what they learn in class, socialization skills, and the rewards of mathematic proficiency. According to Papanastiou and Bottiger (2004) students who participate in these clubs have been found to form more positive attitudes about mathematics and collaborative problemsolving. Additionally, they found that students who participate in clubs are found to have a higher proficiency in mathematics and voluntarily enroll in more math-component courses

According to Jones (1983), mathematics competitions were founded in the U.S. to increase the general public's awareness of the importance of mathematics. When Grugnetti and Juaget (2005) examined competition clubs, it was discovered they teach students to understand mathematical concepts individually, within groups and engage in collaborative problem-solving. Math camps and tutoring are additional ways students can gain math learning outside of the classroom. According to Lerman (2014), math camps and tutoring are useful to increase student success since teachers have less time to help students. Scholars (Topping, Miller, Murray, Henderson, Fortuna \& Conlin, 2011; Westenskow, Boyer-Thurgood \& MoyerPackenham, 2015) examined the effects of the math tutoring and found that many students report having greater desired math attainment, as well as increase parents attitudes and beliefs about mathematics (Binns, Conrad, Polly, \& Algozzine, 2016; Can et al., 2017).

The present study seeks to further examine the relationship between students' participation math activities and math self-efficacy, as well as the effects participation has on proficiency. Thus, the following hypotheses are proposed:

H1: Participation in math based extracurricular activities (camps, clubs, competitions, and tutoring) will result in greater mathematical self-efficacy within ninth-grade students.

H2: Participation in math based extracurricular activities (camps, clubs, competitions, and tutoring) will result in greater mathematical proficiency within ninth-grade students.

\section{METHODS}

\section{Data Source/Sample}

For this study 23,503 ninth grade students were examined from the 2009 High School Longitudinal Study (HSLS) conducted by the National Center for Education Statistics. This data set followed a nationally representative sample of ninth-grade high school students in fall 2009. Overall, 11,973 students (50.94\%) were male, 11,524 students $(49.03 \%)$ were female and 6 students $(0.03 \%)$ did not have a sex designation. According to school demographics collected, 6,689 students $(28.46 \%)$ attended city schools, 8,467 students $(36.03 \%)$ attended suburban schools, 2,788 students (11.86\%) attended town schools and 5,559 students $(23.65 \%)$ attended rural schools. Student race/ethnicity of participants included 165 students $(0.70 \%)$ were American Indian/Alaska Native, 1,952 students (8.31\%) were Asian, 2,450 students (10.42\%) were Black/African American, 3,797 students (16.16\%) were Hispanic, 110 students were Native Hawaiian/Pacific Islander, 12,082 students (51.41\%) were White and 1,941 students $(8.26 \%)$ indicated being of more than one race. A total of 1,006 students (4.28\%) did not have a race designation. 


\section{Measures}

Math Self-Efficacy was measured using the student mathematics self-efficacy measure in the 2009 HSLS dataset. This measure was created from a confirmatory factor analysis of a single factor that was made up of four items that examined the students' confidence in completing math based tests, understanding the textbook, mastering skills, and confidence in doing assignments. To ensure that self-efficacy could be measured as a single factor, a CFA was conducted for the present study which found that the goodness of fit indices was appropriate to use this variable as a single factor. Students responses to the associated items were averaged and the resulting score was standardized so the average student would have an approximate mean score of 0.00 with a standard deviation would be 1 . Scores ranged from -2.92 to 1.62 with a mean of $.04(\mathrm{SD}=1.00)$. A higher score on this measure indicated higher self-efficacy in mathematics.

Math Proficiency was measured using the student mathematics standardized theta score found in the 2009 HSLS dataset. This measure standardized student achievement in math with an average score of approximately 50 and a standard deviation of 10 . Student scores ranged from 24.02 to 82.19 , with a mean of $51.11(\mathrm{SD}=10.08)$. A higher score on this measure indicated higher proficiency in mathematics.

Student Extracurricular Math Activity Involvement was measured by if a student indicated membership in math focused tutoring, camps, clubs or competitions within the previous school year to taking the current survey. Student participation math activities included 670 math club students $(2.85 \%), 1,137$ tutored students $(4.84 \%), 123$ math camp students $(0.52 \%)$, and math competition 874 students $(3.72 \%)$. A total of 2,427 students $(10.33 \%)$ did not have data available for their participation in these activities.

\section{Analytic Plan / Data Analysis}

To address the first hypothesis, structural regression analysis was utilized with student math selfefficacy as the outcome variable and the predictor variables were each of the extracurricular math based activities. The regression equation would be $\widehat{Y}_{\iota}=\beta_{0}+\beta_{1} x_{1 l}+\beta_{2} x_{2 i}-\beta_{3} x_{3 l}+\beta_{4} x_{4 l}+\epsilon_{\iota}$ with $\widehat{Y}_{\iota}$ representing projected math proficiency and $x_{1 l}, x_{2 l}, x_{3 l}$, and $x_{4 l}$ represent if the student took part in math clubs, tutoring, camp and competitions, respectively. Gender, race, and school location were included as controls. To address the second hypothesis, a regression analysis was utilized with student math proficiency as the outcome variable and each of the extracurricular math based activities as the predictor variables. Gender, race, and school location were the control variables in the regression model.

\section{RESULTS}

Results of a confirmatory factor analysis on the four-items representing math self-efficacy indicated that all four items loaded on a single factor with loadings ranging from .78 to .84 . The chi-squared value was found to be 360.56, $\mathrm{p}<.001$ which is significant, but is expected as a result of the sample size. Additionally, RMSEA is .10 which is greater than .05, but both CFI and TLI are above .95 at .99 and .98 respectively.

Results of a structural regression analysis examined the first hypothesis and found that significant negative paths existed between math self-efficacy and involvement in both math club $(\beta=-.06, p<.001)$ and math competition $(\beta=-.11, p<.001)$. Non-significant paths were found between math self-efficacy and both math tutoring $(\beta=.00, p=.67)$ and math camp $(\beta=-.00, p=.67)$ participation. With regards to goodness of fit, the chi-squared value is $405.40, \mathrm{p}<.001$, which would be expected with a large sample of students being utilized. Additionally, RMSEA is .04 which is less than .05 , both CFI and TLI are above .95 at .99 and .98 respectively. Thus, this model can be viewed as being a good fit. For more details on the model see figure 1 . 
FIGURE 1

MODEL EXAMINING ACTIVITIES AND MATH SELF-EFFICACY

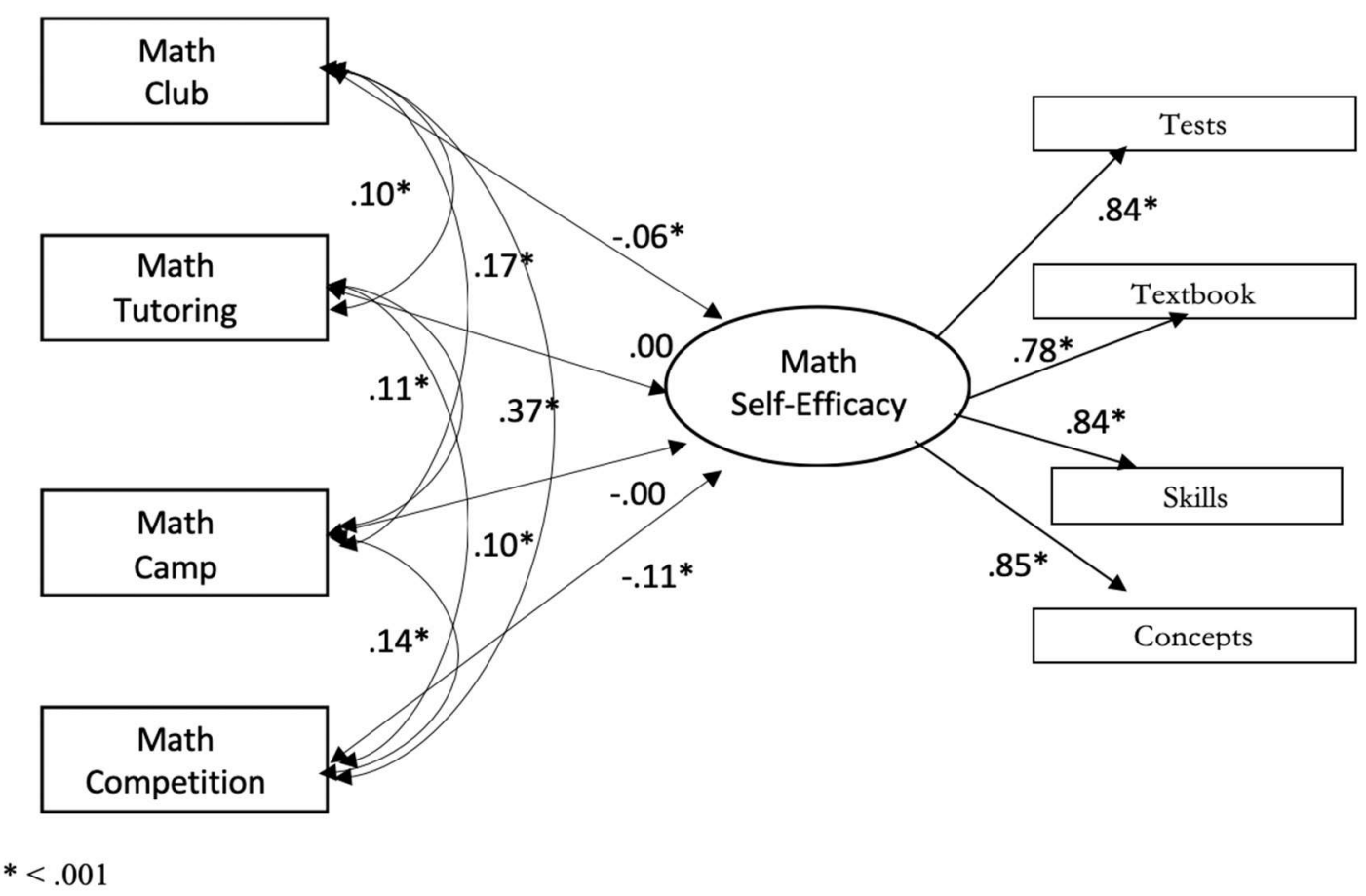

Results of a regression analysis examining the second hypothesis found that there is a significant relationship between math proficiency and being part of a math club $(b=.25, p<.001)$, math camp $(b=$ $2.83, \mathrm{p}<.002)$ and taking part in math competitions $(b=9.80, \mathrm{p}<.001)$. To examine for multicollinearity between predictors, which found the mean VIF $=1.06$, which indicates a minimal risk of multicollinearity. Furthermore, for individuals who indicated having took part in a math club, tutoring or competitions there is an associated 3.50, 0.32 and 9.80 increase respectively in math proficiency. Additionally, for individuals who indicated taking part in a math camp, there is an associated decrease of 2.83 in math proficiency. For further details see Table 1.

TABLE 1

EFFECT OF EXTRACURRICULAR MATH ACTIVITIES ON STUDENT MATH PROFICIENT

\begin{tabular}{lllll}
\hline Math Proficiency & $\beta$ & SE $B$ & $p$ & $t$ \\
\hline Club & 3.50 & .42 & .001 & 8.40 \\
Tutoring & 0.32 & .32 & .290 & 1.05 \\
Camp & -2.83 & .90 & .002 & -3.13 \\
Competitions & 9.80 & .36 & .001 & 26.92 \\
cons & 50.54 & .32 & .001 & 158.11 \\
\hline
\end{tabular}

$R^{2}=.06$, Adj. $R^{2}=.06, F=189.23$

\section{DISCUSSION}

Based on the findings of this study, students' previous involvement in math clubs and competitions results in significant improvement in students' math self-efficacy and proficiency. Additionally, being part 
of a math camp results in a significant improvement in student's proficiency in mathematics. These findings partially support the proposed hypotheses for the present study, since taking part in these activities plays a significant factor in students' self-efficacy and proficiency in math. But, many of these significant relationships are negative rather than positive as proposed. This could be the result of no measure of length of participation in math activities and the questions only addressed participation the previous school year.

In addition, this flaw in the utilized dataset could be the cause of the similar negative effect of taking part in math camp on math proficiency. Hardin (2018) indicates a similar effect for both math clubs and competitions should be noted since the reasons for participation and benefits from participation are similar. Hardin further indicates these two activities have been found to help increase self-efficacy. By addressing participation throughout life and time since participation could help to better understand these relationships. The similar relationship between being part of a club or competition has on math proficiency also further supports the findings of Hardin.

From the present study, the results can be seen as indicating that math clubs and competitions help to increase student math proficiency. Since scholars (Grugnetti \& Juaget, 2005: Lerman, 2014) have indicated these activities have a positive impact on student knowledge in mathematics, the present study can be seen as reinforcing these previous findings that show the importance of clubs and competitions. Further the findings of the present study are useful to encourage the inclusion of such activities into the core math curriculum in elementary and middle school in addition to high school to benefit students earlier in life.

Future studies should examine if the math activities in the present study have a lasting effect on students. Additionally, future studies should examine if the reason some predictors were found to have negative effects on students' self-efficacy is because of decreases in these programs as individuals progress toward high school. In order to address both of these limitations, the activity participation question should ask if the individual has participated in each activity and the period of time since participation. Future studies should also examine the reason for participation in each activity to gather a better understanding regarding if reason for participation could play a factor in the outcomes.

\section{REFERENCES}

Bessant, K.C. (1995). Factors associated with types of mathematics anxiety in college students. Journal for Research in Mathematics Education, 26, 327-345.

Binns, I.C., Polly, D., Conrad, J., \& Algozzine, B. (2016). Student perceptions of a summer ventures in science and mathematics camp experience. School Science and Mathematics, 116, 420-429.

Can, I., Koydemier, S., Durham, S., Ogan, S., Gozukara, C., \& Cokluk, G. (2017). Changing high school students' attitudes towards mathematics in a summer camp: Happiness matters. Educational Sciences: Theory and Practice, 17, 1625-1648.

Graven, M. (2016). Strengthening maths learning dispositions through 'math clubs'. South African Journal of Childhood Education, 5(3), 1-7.

Grigg, S., Perera, H.N., Mcllveen, P., \& Svetleff, Z. (2018). Relations among math self-efficacy, interest, intentions, and achievement: A social cognitive perspective. Contemporary Educational Psychology, 53, 73-86.

Grugnetti, L., \& Jaquet, F. (2005). A mathematical competition as a problem solving and a mathematical education experience. Journal of Mathematical Behavior, 24, 373-384.

Hardin, J. (2018). Fun, not competition: The story of my math club. Journal of Humanistic Mathematics, 8, 350-358.

Jones, M.H. (1983). Mathcounts: A new junior high school mathematics competition. Mathematics Teacher, 76, 482-485.

Lerman, S. (Ed.). (2014). Wait time in mathematics teaching. In Encyclopedia of Mathematics Education (p.641). Houten, Netherlands: Springer.

McKeachie, W.J., Pintrich, P.R., Lin, Y., \& Smith, D. (1986). Teaching and learning in the college classroom: A review of the research literature. Ann Arbor, MI: University of Michigan National Center for Research to Improve Postsecondary Teaching and Learning. 
Morreale, S., Backlund, P., \& Sparks, L. (2014). Communication education and instructional communication: Genesis and evolution as fields of inquiry. Communication Education, 63, 344354. doi: 10.1080/03634523.2014.944926

Murphy, P.K., \& Alexander P.A. (2001). A motivated exploration of motivation terminology. Contemporary Educational Psychology, 25, 3-53.

National center for education statistics. (2009). High school longitudinal study of 2009 [data set and codebook]. Retrieved from https://nces.ed.gov/OnlineCodebook/Session/Codebook/4159ee31471e-434f-9d89-19112958daf2

Topping, K.J., Miller, D., Murray, P., Henderson, S., Fortuna, C., \& Conlin, N. (2011). Outcomes in a randomized controlled trial of mathematics tutoring. Educational Research, 53, 51-63.

Westenskow, A., Boyer-Thurgood, J., \& Moyer-Packenham, P.S. (2015). A window into mathematical support: How parents' perceptions change following observations of mathematics tutoring. Journal of Research in Childhood Education, 29, 458-475.

$\mathrm{Wu}, \mathrm{Y}$. (2016). Universal beliefs and specific practices: Students' math self-efficacy and related factors in the United States and China. International Education Studies, 12, 61-74.

Yuksel-Sahin, F. (2008). Mathematics anxiety among $4^{\text {th }}$ and $5^{\text {th }}$ grade Turkish elementary school students. International Electronic Journal of Mathematics Education, 3, 179-192. 